\title{
Incident Management with Knowledge base: College of computer in Qassim University as a case study
}

\author{
Rinad Al-oqaily', Rehab Alharbi', Shiekha Alnomsi' ${ }^{1}$, Amlak Alharbi ${ }^{1}$, Afef Selmi ${ }^{2}$,* \\ ${ }^{1}$ Bachelor's degree in Information Technology, Department of Information Technology, College of Computer, Qassim University,
} Saudi Arabia.

\begin{abstract}
2,*Assistant Professor, Department of Information Technology, College of Computer, Qassim University, Saudi Arabia. E-mailID: a.selmi@qu.edu.sa, ORCID:0000-0001-9363-7702 (Afef Selmi)
\end{abstract}

\begin{abstract}
Incident management in College of Computer needs to be processed and stored in order to give fast services in terms of solving staff and student's problems and to make the Technical Support Department agent's job easier. Therefore, knowledge base is needed as an incident storage media for the Technical Support Department. This paper propose an Incident Management system using Knowledge base called "COC HelpDesk". The validation of the system is shown through an experiment study carried out by the Technical Support Department agents.
\end{abstract}

Keywords: Incident Management, Helpdesk, Knowledge base.

\section{INTRODUCTION}

The technical support department in Qassim University consists of a group of technicians who are responsible for managing, documenting and tracking incidents. This center provide a list of services such as: installation and maintenance of computers, install and configure operating systems, install the software, install and maintain printers, install and maintain the scanner, maintenance of photocopiers, installation and maintenance of projector and general technical tasks. A workload is therefore imposed on the service center team. The response process, in case of an incident can then be slow. Thus, the method of communication is not well defined in order to circulate information and update team members on status of the incident. Certainly, incident documentation is considered important during the incident management process because it ensures tracking of incidents. In addition, incidents history and their solutions allow sharing experience between teams and avoids the loss of time. Helpdesks serve an important role in the Information Technology Department. It provides the primary point of contact for clients to contact analysts to help them resolve problems. In fact, lack of an automatic process generates various problems that limit the productivity of the technical support office and delay it [1]. These problems are summarized as follow: (i) overload of work that is done by a single agent; (ii) difficult communication between agents, (iii) lack of previous problems and their solutions (iv) time taking to solve repeated problems.

Based on information provided by the technical support department and the visualization of the current process that is still manual, we hence the need to automate the incident management process with methods that are more efficient. In order to solve these problems, it is necessary to propose a tool within the university to have regular monitoring of computer equipment. In fact, our project aims to design and develop an Incident Management system using Knowledge base. It allows automating the incident management process in order to facilitate and optimize the services quality provided by the Technical Support department of the university. The use of knowledge base we allow to gang up time to solve the repeated problems [1]. The main objectives of our COC_HelpDesk solution are: (i) make the Incident management process automatic, (ii) save time through the Knowledge base (problem/solutions), (iii) provide collaboration between agents. The remaining of this paper is organized as follows. Section 2 outlines a literature review. Section 3 describes our proposed Incident Management solution and its experimental study. Finally, section 4 concludes this paper.

\section{LITERATURE REVIEW}

This section aims to explain, first, the main concepts related to our project such as; knowledge management, knowledge management system, help desk, knowledge base and incident management. Second, it outlines the related works.

\subsection{Concepts and definitions}

Knowledge is defined as an information that has been documented by written on papers or stored on a database. Knowledge management use techniques and strategies to create knowledge. Based on [1], the knowledge management process is defined by the following steps: collect knowledge, organize knowledge, store knowledge, make knowledge available and use the knowledge. Knowledge management system collects, organizes and stores information in a knowledge base. It is also an interface between the helpdesk agent and the data. Knowledge base is a repository for information related about a particular subject. Help Desk provides information and administrative support to users where problems managed, assigned, and resolved [2, 3]. Based on [2], the main roles of a helpdesk are (i) provide an environment for easy creating incidents (problems or requests defined through users), (ii) assign the incident to a responsible person, (iii) solve the incident at an appropriate time and good quality. Incident Management is a process recording and resolving accidents. The aim of incident management is to restore the service to the customer as quickly as possible [4]. 


\subsection{Related work}

In the technical support center in Qassim University, the following steps describe the current incident management process. When an incident has occurred, the customer should write a memo of a problem for the maintenance office manually. The maintenance agent sends his memo to technical support. The helpdesk agent receives the request and the problem is resolved if he knows the solution or he asked colleagues about the solution and close the problem. If the problem is new, he searches the solution from the Internet or ask the men section, solves the problem and close the incident. The incident management process is more detailed by the following figure.

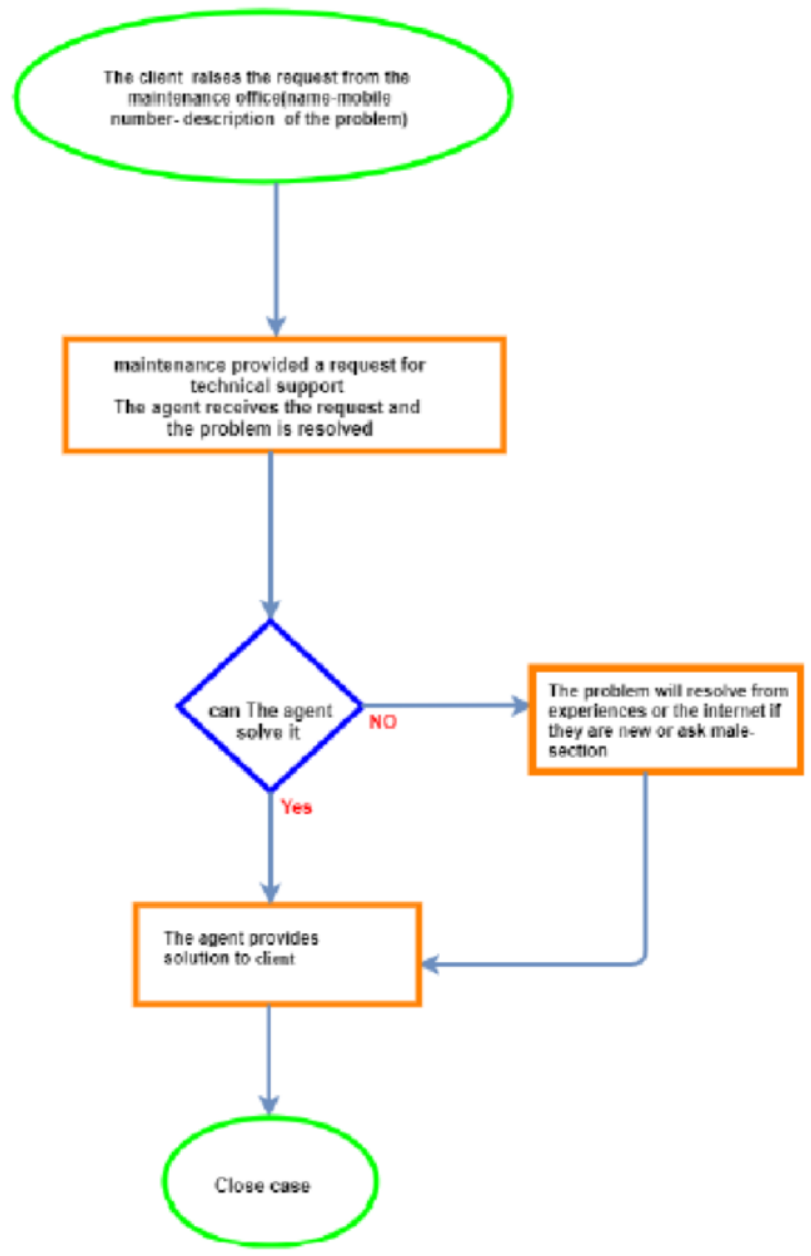

Figure 1: The current workflow of technical support of Qassim University

Different systems have been proposed in the literature. In the following, we present, in chronological order, the most recent works.

The result of this research [5] is interdisciplinary project aiming to develop a comprehensive database of UK museums in existence since 1960. The proposed work presents the challenges they faced: developing the knowledge base, the web application, the methodology and methods, the design and implementation of the system, the outcomes and implications of a user trial undertaken, with a group of experts from the UK's museums sector.
In [6], authors have proposed a system in order to store knowledge into the knowledge base that can be reused by call center officers. It aims to help the officers to solve customer's problems faster and more accurate. This model gives a structure to the knowledge, which can be used as training material for call center officers.

In this work [7], authors propose to adopt best practice from incident management framework to academic information system by built system on a web platform. System design include (use case diagram, use case scenario and database design).

The proposed system in [2] is an intelligent system for ordering incidents in a Helpdesk system. The main goals for this system are (i) evaluate the overall importance of each incident,

(ii) order the incidents by their importance and (iii) show the ordered incident list to solvers. The proposed system helps solvers to recognize the most important incidents (proposed by expert system) and to make a decision about priority in processing and solving incidents.

The result of this research [8] is "to create a single point of access for IT support for staff and students alongside nonacademic student enquiries". A single point of contact supporting staff and students with their IT enquires, as well as continuing the current job of the student support desk for nonIT matters. Essentially this would be a fusion of the IT Helpdesk function with the student Information desk.

In the following, we present a comparative study of the recent systems presented above. Table 1 shows the comparison between these systems using these criteria: use knowledge base, incident management and the methodology used.

Table 1: Comparison of previous studies

\begin{tabular}{|l|l|l|l|}
\hline $\begin{array}{l}\text { Use } \\
\text { Knowledge } \\
\text { base }\end{array}$ & $\begin{array}{l}\text { Incident } \\
\text { management }\end{array}$ & Methodology \\
\hline$[5]$ & $*$ & - & $\begin{array}{l}\text { Data collection, Conceptual } \\
\text { modelling, Developing the } \\
\text { Knowledge Base, Developing } \\
\text { the Web Application }\end{array}$ \\
\hline$[6]$ & $*$ & $*$ & $\begin{array}{l}\text { Kitchenham's method, } \\
\text { Planning review, } \\
\text { Identifying the objective, } \\
\text { teveloping the review } \\
\text { protocol, Implementation, }\end{array}$ \\
\hline$[7]$ & - & $\begin{array}{l}\text { Identification of research } \\
\text { Selection process, Study } \\
\text { quality assessment, Data } \\
\text { extraction and monitoring, } \\
\text { Data synthesis, Reporting }\end{array}$ \\
\hline & $*$ & $\begin{array}{l}\text { Requirement Elicitation, } \\
\text { System Design, Confirmation } \\
\text { of System Design to } \\
\text { Stakeholder, System } \\
\text { Development, Evaluation }\end{array}$ \\
\hline & & &
\end{tabular}




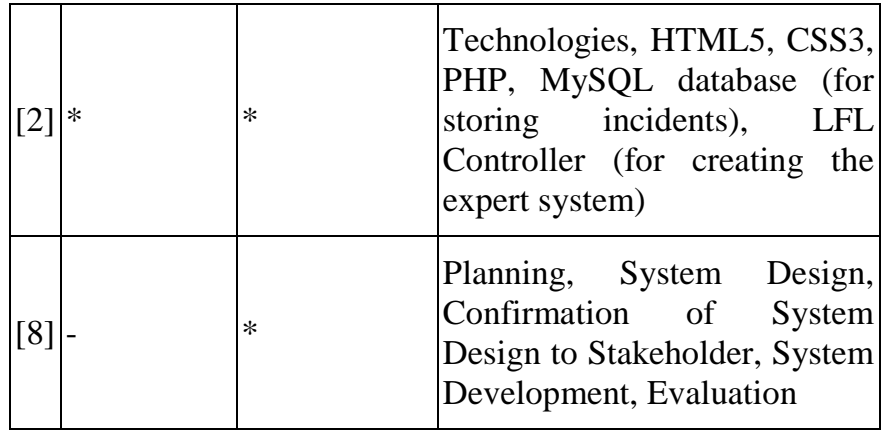

According to this table, we conclude that:

- Most proposed systems use the knowledge base to manage the incident.

- The methodology used mostly is the software development lifecycle (SDLC).

Inspiring of these systems, we think that it is very important to use knowledge base to manage incidents. This saves time by using solutions to previous problems.

\section{CONTRIBUTION}

In Technical Support Department, Incident Management is the process responsible to manage the lifecycle of all incident. The main objectives of the Incident Management process are: (i) restore normal service operation to make the process automatic, (ii) save time through the Knowledge base (restore the previous problem/solutions), (iii) provide collaboration between agents to maintain the services quality provided by the department.

In the following, we present our contribution, which aims to design and develop an Incident Management system using Knowledge base to facilitate and optimize the quality and performance of the services provided by the university. First, we describe the architecture of $C_{0} C_{-}$HelpDesk and its modules and the Incident Management process. Second, we evaluate the system by performing a simulation sessions in the Technical Support Department of the college.

\subsection{Coc_HelpDesk proposal}

The main objective of our work is to propose a new solution for incident management. Our project aims to design and develop an Incident Management system using Knowledge base called COC_HelpDesk (College of Computer HelpDesk).

COC_HelpDesk system is proposed to automate the incident management process in order to facilitate and optimize the quality and performance of the services provided by the university.

The following figure shows the main modules of the proposed system.

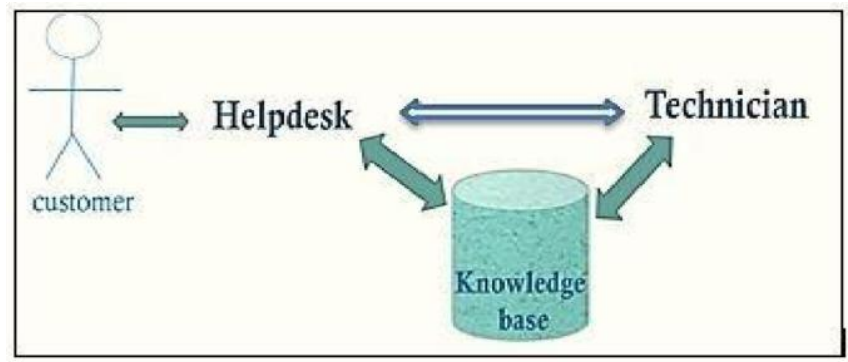

Figure 2: COC_HelpDesk architecture

In fact, the proposed solution contains two modules: a "Claim module" and a "Diagnostic repair module".

- Claim module: at this level, a helpdesk receive a claim where he will enter the information relating to this claim. $\mathrm{He}$ is going, first, to search the incident solution in the knowledge base to respond to staff requests and all technical or functional issues related to the use of tools. Otherwise, he will send the claim to the concerned parties with the ability to view the status of the claim every time.

- Diagnostic repair module: the technician will receive a notification of problems asked to make the diagnostics and determine the failure and save it. Then, he proposes the solution to be implemented and save it in the knowledge base. Then he closes the incident.

Our incident management processes is described in the following figure.

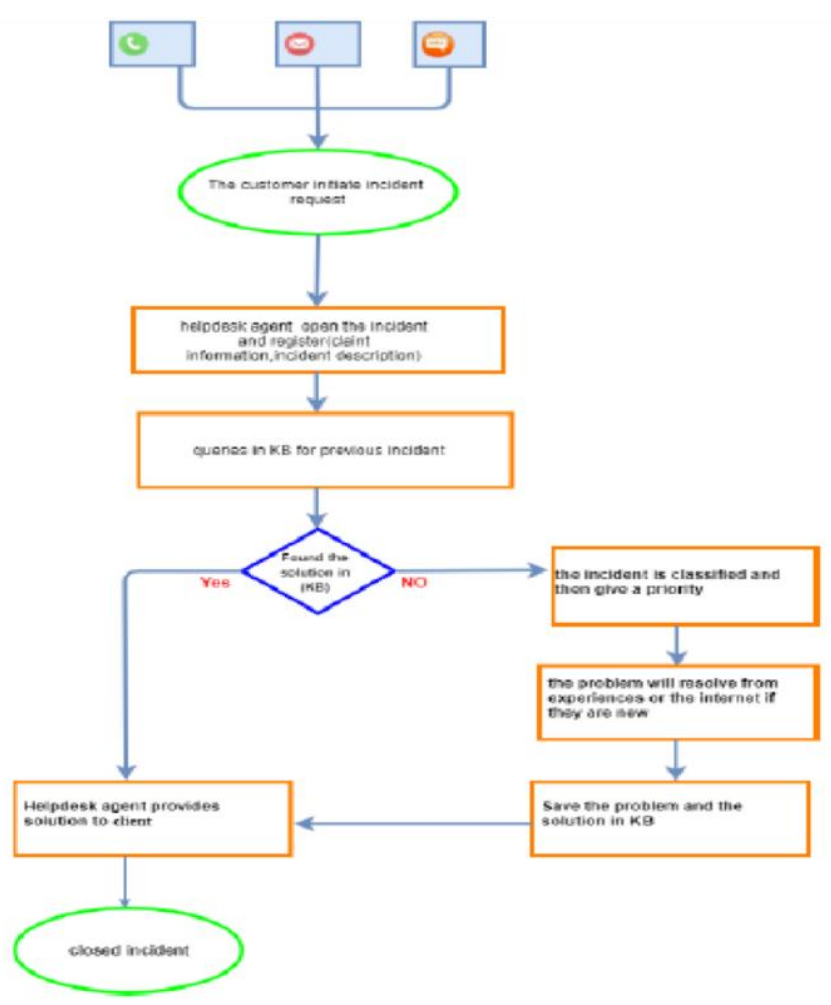

Figure 3: COC_HelpDesk processes 


\subsection{Evaluation}

In order to evaluate the performance of the proposed COC_HelpDesk system, simulations session have been performed in the Technical Support Department of the College of Computer (female section) at Qassim University. Stakeholders of this session are the dean and a list of agents (6 persons) of the department.

The different agents have run the system in accordance with their respective roles with the Incident Management case study. The results of the simulations session proved the performance of our system in terms of incident management and response time. The dean of the department proved that the system is feasible to use and understand and it has a readable interface. Other agents proved that the system contains all excepted functions for incident management and responds within the excepted time.

The following figure represent some screenshots of COC_helpDesk.

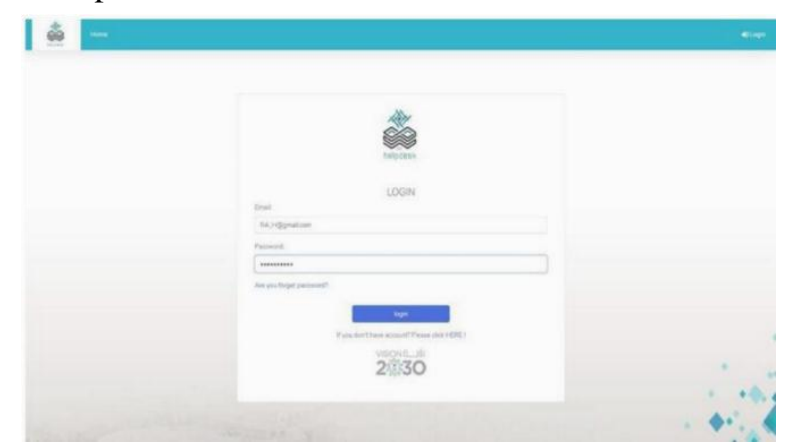

(a)

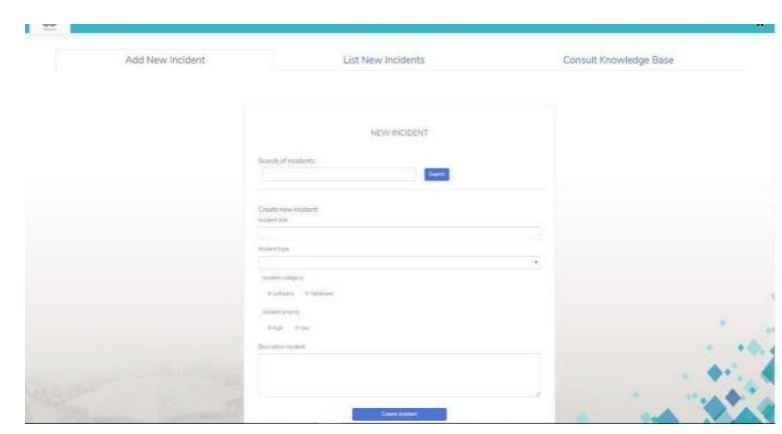

(b)

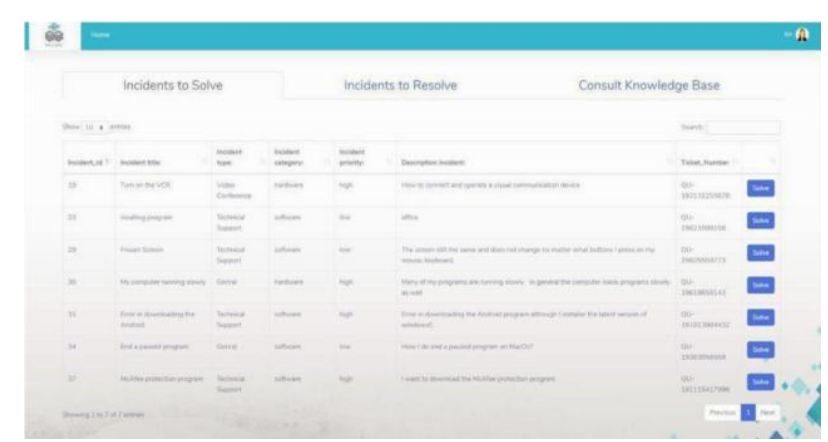

(c)

Figure 4: Screenshot of the systems. (a) UI for Login. (b) UI for Add new incident. (c) UI for resolve incident.

\section{CONCLUSION}

This paper proposed an incident management solution using Knowledge base. The proposed COC_HelpDesk aims to facilitate and optimize the services quality provided by the IT department of College of Computer of Qassim University.

COC_HelpDesk is designed with consideration of the needs of the Technical Support Department of the college. The built system has automated the incident management process and save time to resolve incidents by using the knowledge base.

Simulation sessions are done by running all excepted functions for incident management.

These simulations are done by the dean and a set of agents of the Technical Support Department. The obtained results confirm our contribution for incident management in the department.

\section{ACKNOWLEDGMENT}

For financial support, our thanks to the Department of Information technology, College of Computer, Qassim University, Kingdom of Saudi Arabia.

\section{REFERENCES}

[1] L. M. González, R. E. Giachetti, and G. Ramirez, "Knowledge management-centric help desk: Specification and performance evaluation," Decis. Support Syst., vol. 40, no. 2, pp. 389-405, 2005.

[2] B. Walek, "Intelligent System for Ordering Incidents in Helpdesk System," ICSEC 2017 - 21st Int.Comput. Sci. Eng. Conf. 2017, Proceeding, vol. 6, pp. 224-228, 2018.

[3] R. P. Masongsong and M. A. E. Damian, "Help Desk Management System," Proc. World Congr.Eng. Comput. Sci. 2016 Vol I, vol. 1, 2016.

[4] "ITIL - A guide to incident management What is incident management? What are the differences between incident management and," pp. 1-7.

[5] A. Creating, A. Poulovassilis, N. Larsson, F. Candlin, and J. Larkin, "BIROn - Birkbeck Institutional Research Online through Rapid Application Development," 2019 ..

[6] N. N. Annisa, D. I. Sensuse, and I. Wilarso, "Knowledge Base Model for Call Center Department : A Literature Review," 2018 Int. Conf. Inf. Technol. Syst. Innov., pp. 242-247, 2018.

[7] I. K. Raharjana, "Incident and Service Request Management for Academic Information System based on COBIT," 2018 5th Int. Conf. Electr. Eng. Comput. Sci. Informatics, pp. 421-425, 2018.

[8] B. Eidam, A. Russell, N. Burden, and J. Powell, "University of Exeter application for UCISA Award for Excellence 2014 Unifying the Student Services and IT Help Desk Functions Initial stages of the project - how are we going to achieve this ?," pp. 1-8, 2014. 